\title{
Optimum dose of olsalazine for maintaining remission in ulcerative colitis
}

\author{
S P L Travis, C Tysk, H J de Silva, H Sandberg-Gertzén, D P Jewell, G Järnerot
}

\begin{abstract}
To evaluate the optimum dose of olsalazine for maintaining remission in ulcerative colitis, 198 patients in remission for more than three months were randomly assigned to receive $0.5 \mathrm{~g}, 1.0 \mathrm{~g}$, or $2.0 \mathrm{~g} /$ day for 12 months. A dose-ranging effect was detected in the per protocol analysis, with remission rates of $60 \%(0.5$ g), $70 \%(1 \cdot 0 \mathrm{~g})$, and $78 \%(2 \cdot 0 \mathrm{~g})(\mathrm{p}=0 \cdot 03$, trend in proportions). The higher dose was most effective in patients with proctitis $(90 \%$ remission on 2 g/day, $\mathbf{p}=\mathbf{0 . 0 3}$ ) or those in remission for less than 12 months before the trial $(88 \%$ remission on $2 \mathrm{~g} / \mathrm{day}, \mathrm{p}=0.0006)$. There was little dose-ranging effect in patients with extensive colitis or those in remission for more than 12 months. Diarrhoea necessitated treatment withdrawal in $12 \%$. The optimal dose of olsalazine for maintaining remission in ulcerative colitis is $1 \mathrm{~g} / \mathrm{day}$. For patients with proctitis or recent relapse, 2 g/day may be preferable, although the dose seems to be less important in patients with more extensive disease or those in long term remission. (Gut 1994; 35: 1282-1286)
\end{abstract}

Olsalazine was developed as an alternative to sulphasalazine for the treatment of ulcerative colitis, in order to avoid the side effects of sulphasalazine attributable to the sulphapyridine moiety. ${ }^{12}$ The drug consists of two molecules of 5-aminosalicylic acid (5-ASA) joined by an azo bond that is split by bacterial azoreductase to release 5-ASA in the colon. ${ }^{3}$ Olsalazine is now well established in the treatment of ulcerative colitis. A dose of $1 \mathrm{~g} /$ day compared with placebo reduced the six month relapse rate from $45 \%$ to $23 \%$ in a randomised trial of 160 patients who were intolerant of sulphasalazine, ${ }^{4}$ and in another study of 162 patients, olsalazine $1 \mathrm{~g}$ /day was as effective as sulphasalazine $2 \mathrm{~g} /$ day for maintaining remission. ${ }^{5}$ This has since been confirmed. ${ }^{6}$ Olsalazine is well tolerated by over $80 \%$ of patients who are intolerant of sulphasalazine. ${ }^{4}$

For maintaining remission with sulphasalazine, Azad Khan et al ${ }^{7}$ showed that greater therapeutic efficacy could be obtained by increasing the dose, although $2 \mathrm{~g}$ daily was optimal in terms of efficacy with the least side effects. However, whether there is a similar dose response effect for olsalazine when used for maintenance therapy is unknown. In a small study of 66 patients with active ulcerative colitis treated with olsalazine, a higher dose
( $3 \mathrm{~g} /$ day) was more effective than $1.5 \mathrm{~g}, 0.75 \mathrm{~g}$, or placebo. ${ }^{8}$ Consequently, a dose-ranging study of olsalazine in the maintenance of remission in ulcerative colitis was designed. Particular attention was paid to the relationship between dose efficacy and the extent of disease and the safety profile of different doses, in view of reports that a small intestinal secretory diarrhoea may be induced by olsalazine. ${ }^{9}$

\section{Methods}

\section{PATIENTS}

A total of 198 patients from Oxford or Örebro (99 from each centre) with ulcerative colitis in remission for three or more months were recruited. Ulcerative colitis was diagnosed on standard clinical, endoscopic, histological, and radiological criteria, and remission was defined as no clinical symptoms of active disease and no signs of active inflammation on sigmoidoscopy (grade 0 : normal; 1 : pink mucosa of quiescent colitis, without visible vessels). ${ }^{10}$ The maximum extent of macroscopic disease ever recorded by endoscopy or barium enema was defined as proctitis ( $\leqslant 15 \mathrm{~cm})$, left sided (up to the splenic flexure), or subtotal/pancolitis. The study was approved by the ethical committee of each centre.

PROTOCOL

Each patient was randomly assigned to one of three groups receiving $0.5 \mathrm{~g}, 1.0 \mathrm{~g}$, or $2.0 \mathrm{~g}$ enteric coated tablets of olsalazine daily. Tablets were supplied in blister packs and patients were instructed to take two tablets twice daily with food. Each active tablet contained $500 \mathrm{mg}$ olsalazine sodium. Physically indistinguishable placebo tablets (cornstarch and riboflavin sodium phosphate) made up the numbers for patients randomised to $0.5 \mathrm{~g}$ or $1.0 \mathrm{~g} /$ day and to allow the dose to increase gradually over seven days for those randomised to $2.0 \mathrm{~g} /$ day in order to improve patient tolerance. Patients were assessed clinically at three monthly intervals for 12 months, or within three weeks if symptoms of a relapse occurred. The primary end point of efficacy was relapse, defined as an increase in bowel frequency with blood or mucus and evidence of active disease on sigmoidoscopy. The time in remission from the start of treatment was regarded as a secondary endpoint. Safety assessments included questioning for possible adverse reactions at each visit and laboratory measurements of full blood count, erythrocyte 
TABLE I Baseline characteristics of patients

\begin{tabular}{|c|c|c|c|}
\hline & \multicolumn{3}{|c|}{ Dose of olsalazine } \\
\hline & $0.5 \mathrm{~g}$ & $1.0 \mathrm{~g}$ & $2 \cdot 0 \mathrm{~g}$ \\
\hline \multicolumn{4}{|l|}{ Patient demographics $(n=194)$ : } \\
\hline Male/female & $40 / 27$ & $42 / 23$ & $32 / 30$ \\
\hline Age (mean (SD)) & $50(13)$ & $46(12)$ & $49(12)$ \\
\hline Smokers & 8 & 9 & 7 \\
\hline Snuff takers & 5 & 1 & 2 \\
\hline \multicolumn{4}{|l|}{ Ulcerative colitis history: } \\
\hline Disease duration (median (range), y) & $13(1-42)$ & $12(1-31)$ & $10(1-39)$ \\
\hline Remission (median (range), mth) & $34(3-243)$ & $18(3-253)$ & $21(3-258)$ \\
\hline \multicolumn{4}{|l|}{ Maximum extent of disease: } \\
\hline Proctitis & 11 & 8 & 14 \\
\hline Left sided & 30 & 33 & 30 \\
\hline Subtotal/total & 26 & 24 & 18 \\
\hline \multicolumn{4}{|l|}{ Previous relapse preventing treatment: } \\
\hline Sulphasalazine & 47 & 49 & 46 \\
\hline Mesalazine & 6 & 7 & 2 \\
\hline Olsalazine & 10 & 6 & 9 \\
\hline None & 4 & 3 & 5 \\
\hline \multicolumn{4}{|l|}{ Sigmoidoscopic findings: } \\
\hline Grade 0 & 44 & 45 & 43 \\
\hline Grade 1 & 23 & 20 & 19 \\
\hline
\end{tabular}

sedimentation rate, creatinine, liver function tests, and urine for protein or blood.

\section{ANALYSIS}

The sample size was based on estimates that the relapse rates would be $55 \%$ in the $0.5 \mathrm{~g}$ group, $36 \%$ in the $1.0 \mathrm{~g}$ group, and $28 \%$ in the $2.0 \mathrm{~g}$ group. Using a one sided test with a significance level of $5 \%$ and a power of $80 \%$, 60 patients in each group were needed and $10 \%$ was added to this number to allow for 'drop outs'. The test for trend in proportions described by Armitage ${ }^{11}$ was used in analyses of relapse (per protocol (PP) analysis) and failure (intention to treat (ITT) analysis). Two subgroup analyses were performed with respect to the maximum extent of disease and duration of remission before the study.

\section{Results}

BASELINE CHARACTERISTICS

There were no significant differences between patients in the different dosage group (Table I). There was, however, a statistically non-significant trend $(p=0 \cdot 17)$ for patients in the $0.5 \mathrm{~g} /$ day group to have been in longer remission than those in the other two groups. More patients smoked or took snuff in Örebro (25 of 98) than Oxford (seven of 96, $\mathrm{p}<0.001$ ), and proctitis was more common in Oxford (25 of 96, versus eight of 98 in Örebro, $\mathrm{p}<0.001)$. Otherwise, patients from the two centres were similar. All but 13 patients were on some form of maintenance treatment (Table I).

TABLE II Relapse rates according to dose of olsalazine

\begin{tabular}{|c|c|c|c|}
\hline & \multicolumn{3}{|l|}{ Dose } \\
\hline & $0.5 \mathrm{~g}$ & $1.0 \mathrm{~g}$ & $2.0 \mathrm{~g}$ \\
\hline $\begin{array}{l}\text { Failure rate (ITT-analysis) }(n=194) \text { : } \\
\text { Total no of patients } \\
\text { No }(\%) \text { relapsing } \\
\text { No }(\%) \text { withdrawals } \\
\text { Relapse rate (PP-analysis) }(n=155) \text { : }\end{array}$ & $\begin{array}{l}67 \\
22(33) \\
13(19)\end{array}$ & $\begin{array}{l}65 \\
17(26) \\
9(14)\end{array}$ & $\begin{array}{l}62 \\
10(16) \\
15(24)\end{array}$ \\
\hline $\begin{array}{l}\text { Total no of patients } \\
\text { No }(\%) \text { relapsing }\end{array}$ & $\begin{array}{l}53 \\
21(40)\end{array}$ & $\begin{array}{l}56 \\
17(30)\end{array}$ & $\begin{array}{l}46 \\
10(22)\end{array}$ \\
\hline
\end{tabular}

ITT $=$ intention to treat; $\mathrm{PP}=$ per protocol.

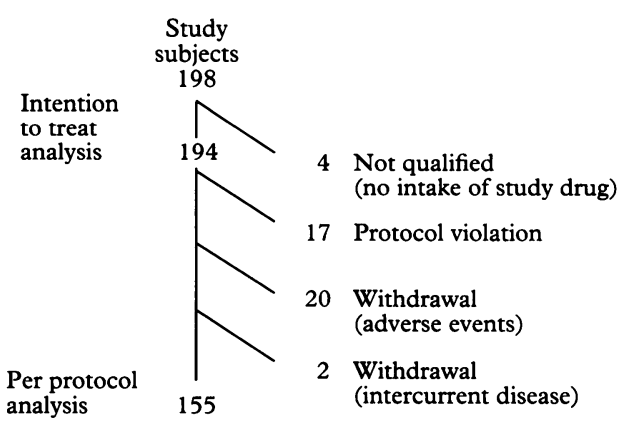

Figure 1: Patient classification and reasons for withdrawal from the study.

PATIENT CLASSIFICATION

The classification of patients for analysis is shown in Figure 1. Four patients were excluded from the analysis because they changed their mind and took no study drug (3) or failed to attend any appointment after the initial visit (1). Seventeen patients were excluded from the PP life table analysis because of non-compliance, concomitant medication, or lack of confirmation of remission or relapse by sigmoidoscopy within three weeks of termination of the trial. Another 22 patients were excluded from the PP relapse rate analysis because of withdrawal for adverse reactions (20) or intercurrent disease (2). Noncompliance was assessed by tablet counting and did not exceed 45 doses $(25 \%)$ in a three month period in any patient.

\section{RELAPSE RATE ANALYSIS}

There was a significant decrease in relapse frequencies when the dose ranged from $0.5 \mathrm{~g}$ to $2.0 \mathrm{~g} /$ day (Table II, PP analysis, $\mathrm{p}=0.03$ ), although the tendency towards a decrease in failure rates did not reach statistical significance (ITT analysis, Table II, $p=0 \cdot 12$ ). The discrepancy between the number of patients relapsing in Table II and the total number of withdrawals from the ITT analysis is explained by one patient who successfully completed the trial but did not have a sigmoidoscopy, who is therefore classified in the ITT analysis as in remission but excluded from the PP analysis, and another who was withdrawn from treatment for intercurrent disease and classified as an ITT relapse, but excluded from the PP analysis.

\section{LIFETABLE ANALYSIS}

Remission curves for ITT and PP analyses for the three doses are shown in Figure 2. Median (range) times to relapse in the PP analysis were 168 (25-378), 174 (14-365), and 191 (50-287) days respectively for $0.5 \mathrm{~g}, 1.0 \mathrm{~g}$, and $2.0 \mathrm{~g}$ doses, which indicates no major differences between the doses for the duration of remission maintained.

\section{REMISSION AND EXTENT OF DISEASE}

When remission after 12 months' treatment was examined according to the extent of 
TABLE III Remission and extent of disease (per protocol analysis)*

\begin{tabular}{|c|c|c|c|c|}
\hline & \multicolumn{3}{|c|}{ Dose of olsalazine } & \multirow[b]{2}{*}{ pt } \\
\hline & $0.5 \mathrm{~g}$ & $1.0 \mathrm{~g}$ & $2 \cdot 0 \mathrm{~g}$ & \\
\hline \multicolumn{5}{|l|}{ Proctitis $(n=26)$ : } \\
\hline Total no of patients & & & & \\
\hline No $(\%)$ remission at $12 \mathrm{mth}$ & $4(50)$ & $5(63)$ & $9(90)$ & 0.03 \\
\hline \multicolumn{5}{|l|}{ Left sided colitis $(n=79)$ : } \\
\hline Total no of patients & 26 & & & \\
\hline No $(\%)$ remission at $12 \mathrm{mth}$ & $13(50)$ & $21(75)$ & $19(76)$ & 0.06 \\
\hline \multicolumn{5}{|l|}{ Subtotal/total colitis $(n=50)$} \\
\hline Total no of patients & 19 & 20 & & \\
\hline No $(\%)$ remission at $12 \mathrm{mth}$ & $15(79)$ & $13(65)$ & $8(73)$ & 0.37 \\
\hline
\end{tabular}

${ }^{\star}$ In the intention to treat analysis the dose ranging effect was significant $(p=0.05)$ for those with proctitis, but not the other groups.

tp Value test for trend in proportion.

disease (Table III, PP analysis), a significant dose-ranging effect was seen for patients with proctitis. Numbers in the proctitis subgroup were relatively small, and when all patients with disease distal to the splenic flexure were examined $(n=105)$, remission rates at 12 months were 50,72 , and $80 \%$ for the $0.5 \mathrm{~g}$, $1.0 \mathrm{~g}$, and $2.0 \mathrm{~g} /$ day groups respectively $(p=0 \cdot 04)$. Dose seemed less important for those with more extensive disease (Table III, PP analysis) and this unexpected finding led to
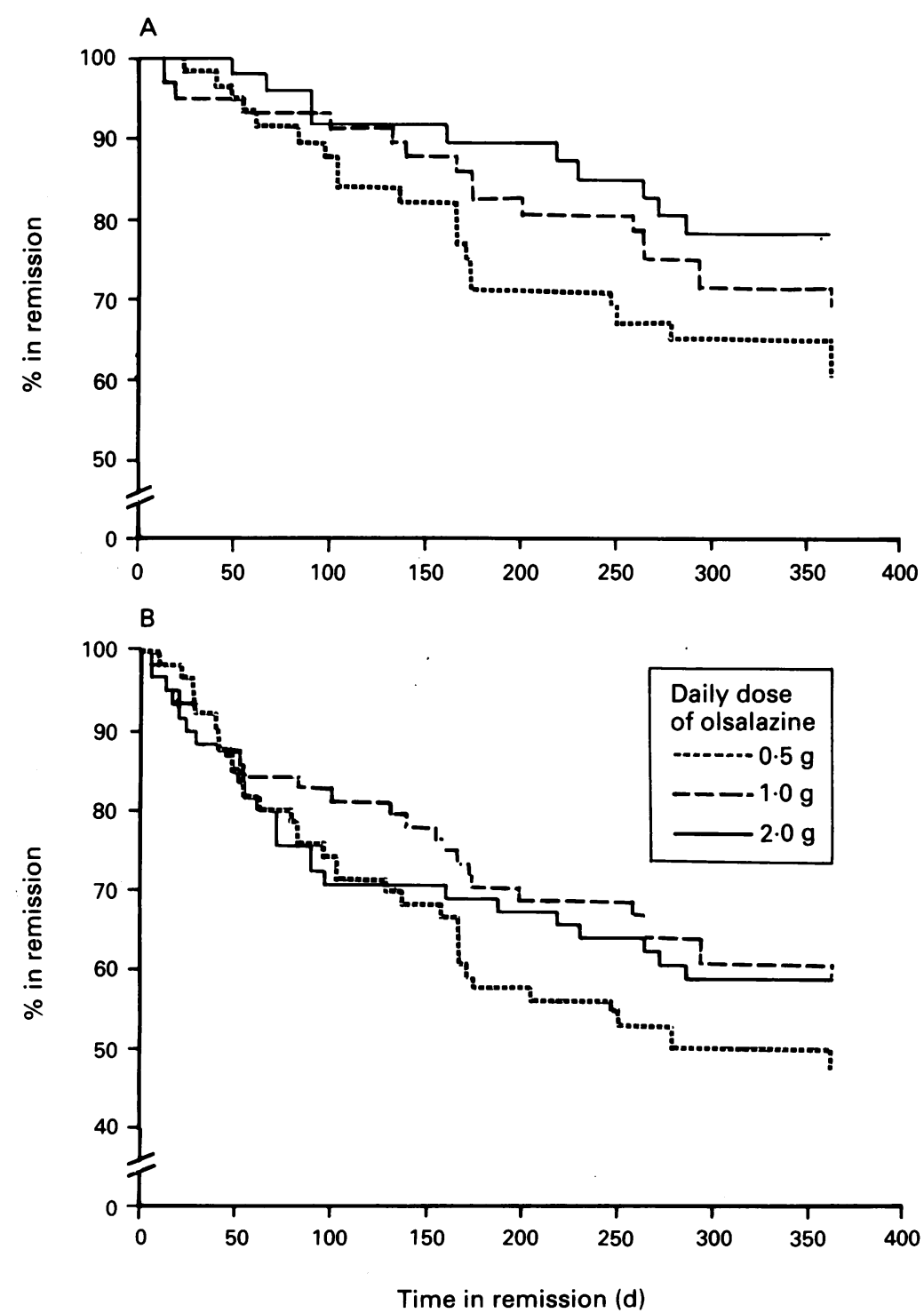

Figure 2: Lifetable analysis. Remission curves for intention to treat $(p=0 \cdot 12$ for trend in proportions) $(A)$ and per protocol $(=0.03)(B)$ analyses. a further analysis of these patients. This showed that the median times in remission before entering the trial were $61 \cdot 0(7 \cdot 3-241 \cdot 7)$ in the $0.5 \mathrm{~g} /$ day group, $24.4(4.6-253.0)$ in the $1.0 \mathrm{~g}$ /day group, and $22 \cdot 8(4 \cdot 3-158.5)$ months in the $2.0 \mathrm{~g} /$ day group, respectively. Although these differences were not statistically significant, possibly because of small numbers, they may still have had an impact on the results.

RELAPSE AND DURATION OF REMISSION

A higher dose was most effective in preventing relapse for those patients who had been in remission for less than a year before the start of the study (Table IV). Dose seemed to be less important for those in longer term remission. There was no initial difference in sigmoidoscopic appearances between patients in short $(<12$ months) and long (>12 months) term remission: $68 \%$ of all patients analysed $P P$ had normal rectal mucosa (grade 0) at the start of the trial, and for those in short or long term remission, the proportions were $60 \%$ and $72 \%$ respectively.

\section{ADVERSE EVENTS}

Adverse events were reported in 90 patients (30 in the $0.5 \mathrm{~g}$ group, 26 in the $1.0 \mathrm{~g}$ group, and 34 in the 2.0 g group). Thirty two patients withdrew prematurely because of adverse events. Apart from diarrhoea or loose stools (Table V), events leading to withdrawal were upper respiratory symptoms (3), abdominal pain (2), tinnitus (1), nausea (1), back pain (1), and constipation (1). The frequency of diarrhoea leading to withdrawal was related to dose and the duration of remission, but not to the extent of disease (Table V). There were no alterations in haematological or biochemical measurements.

\section{CENTRES}

There were no significant differences in results between Örebro or Oxford.

\section{Discussion}

This study shows a trend towards a lower relapse rate for all patients with ulcerative colitis as the dose of olsalazine ranges from $0.5 \mathrm{~g}$ to $2.0 \mathrm{~g}$, and demonstrates a significant benefit of a higher dose ( $2 \mathrm{~g} /$ day) when treating patients with proctitis or within a year of relapse. The intention to treat analysis includes all patients, excluding four who took no study drug or did not attend after the entry visit. Patients who experienced a relapse or were prematurely withdrawn from treatment were classified as failures in this analysis and the trend in proportions of failures just failed to reach statistical significance $(p=0 \cdot 12$, Table II). In the per protocol analysis of 155 patients who reached the study end points (remission at 12 months or documented relapse), a significant dose ranging effect was observed ( $p=0.030$, Table II). The $70-79 \%$ remission rate at 12 months in patients taking 
TABLE IV Relapse and duration of previous remission (per protocol analysis)

\begin{tabular}{|c|c|c|c|c|}
\hline & \multicolumn{3}{|c|}{ Dose of olsalazine } & \multirow[b]{2}{*}{$p^{\star}$} \\
\hline & $0.5 \mathrm{~g}$ & $1.0 \mathrm{~g}$ & $2 \cdot 0 \mathrm{~g}$ & \\
\hline \multicolumn{5}{|l|}{ Remission $<12$ mth $(n=52) t:$} \\
\hline Total no of patients & & & & \multirow{3}{*}{0.0006} \\
\hline No $(\%)$ remission at $12 \mathrm{mth}$ & $3(21)$ & $16(73)$ & $14(88)$ & \\
\hline No $(\%)$ relapse & $11(79)$ & $6(27)$ & $2(12)$ & \\
\hline \multicolumn{5}{|l|}{ Remission $12-24 \mathrm{mth}(\mathrm{n}=36)$ : } \\
\hline Total no of patients & 12 & 14 & 10 & \multirow{3}{*}{$0 \cdot 23$} \\
\hline No $(\%)$ remission at $12 \mathrm{mth}$ & $8(67)$ & $9(64)$ & $8(80)$ & \\
\hline No (\%) relapse & $4(33)$ & $5(36)$ & $2(20)$ & \\
\hline \multicolumn{5}{|l|}{ Remission $>24$ mth $(n=67)$ : } \\
\hline Total no of patients & & 20 & 20 & \multirow{3}{*}{$0 \cdot 29$} \\
\hline No $(\%)$ remission at $12 \mathrm{mth}$ & $21(78)$ & $14(70)$ & $14(70)$ & \\
\hline No $(\%)$ relapse & $6(22)$ & $6(30)$ & $6(30)$ & \\
\hline
\end{tabular}

${ }^{\star} \mathrm{p}$ Value test for trend in proportion.

tAlso significant $(=0.003)$ in the intention to treat analysis.

1 or $2 \mathrm{~g} /$ day is consistent with previous six month studies comparing olsalazine with placebo $^{4}$ or sulphasalazine ${ }^{5}$ over a six month period. In another study comparing 2 g/day balsalazide $(0.7 \mathrm{~g} 5$-ASA $)$ to $4 \mathrm{~g} /$ day balsalazide, remission rates after 12 months were $45 \%$ and $64 \%$ respectively. ${ }^{12}$ The $2 \mathrm{~g}$ balsalazide result is very similar to the one with $0.5 \mathrm{~g} /$ day olsalazine $(0.44 \mathrm{~g}$ 5-ASA), which supports the conclusion in a recent review ${ }^{13}$ that at least $0.8 \mathrm{~g} /$ day 5 -ASA should be delivered in the colon to maintain remission.

Patients with proctitis showed a more pronounced dose ranging response than those with subtotal or pancolitis (Table III). Although numbers in the subgroups are small, this is probably a true response because it is consistent with the pharmacokinetics of olsalazine. Olsalazine is split into component 5-ASA molecules by bacterial azoreductase when the compound reaches the caecum. ${ }^{314}$ Maintenance of remission probably depends on the luminal concentration of 5-ASA in the affected area of the colon since it has a local mechanism of action. ${ }^{15}$ The only study that has examined the colonic distribution of 5-ASA after oral ingestion shows a serial decrease in mucosal concentrations distal to the caecum. ${ }^{16}$ This study is difficult to interpret, however, as it was performed during accelerated intestinal transit and colonic washout and, furthermore, the concentrations did not bear any relationship to the clinical efficacy of different drugs. Higher doses of olsalazine are more likely to achieve therapeutic concentrations of 5-ASA in the distal colon, which is consistent with the greater benefit of $2 \mathrm{~g} /$ day in patients with proctitis. In

TABLE V Withdrawals as a result of diarrhoea or loose stools (intention to treat analysis)

\begin{tabular}{llll}
\hline & \multicolumn{3}{l}{ Dose of olsalazine } \\
\cline { 2 - 4 } & $0 \cdot 5 g$ & $1 \cdot 0 g$ & $2 \cdot 0 g$ \\
\hline Diarrhoea/loose stools: & 67 & 65 & 62 \\
$\quad$ Total no of patients & $16(24)$ & $16(25)$ & $23(37)$ \\
$\quad$ No (\%) reported events & $6(9)$ & $6(9)$ & $12(19)$ \\
$\quad$ No (\%) withdrawals & $10(3-22)$ & $28(2-107)$ & $8(1-42)$ \\
Onset: & $0 / 16(0)$ & $1 / 23(4)$ & $3 / 9(16)$ \\
$\quad$ Median (range) day & $0 / 12(0)$ & $1 / 16(6)$ & $2 / 14(14)$ \\
Related to duration of previous remission (no (\%)): & $6 / 39(15)$ & $4 / 26(15)$ & $7 / 29(29)$ \\
$\quad$ 0-12 Mth & $2 / 11(18)$ & $0 / 8(0)$ & $3 / 17(18)$ \\
$\quad$ 12-24 Mth & $0 / 30(0)$ & $3 / 33(9)$ & $4 / 30(13)$ \\
Related to extent of disease (no (\%)): & $4 / 26(15)$ & $3 / 27(12)$ & $5 / 18(28)$ \\
$\quad$ Proctitis & & & \\
$\quad$ Left sided colitis & & & \\
Subtotal/total & &
\end{tabular}

patients with left sided colitis, no benefit was obtained by increasing the dose from $1 \mathrm{~g}$ to $2 \mathrm{~g} /$ day.

The results in patients with subtotal or pancolitis are more difficult to interpret as there was no difference between dosage groups. This is possibly because patients in the $0.5 \mathrm{~g} /$ day group tended to have a longer median time in remission before entering the study. Patients who had recently relapsed were more sensitive to the dose of olsalazine. In those who had been in remission for less than 12 months, a high dose ( $2 \mathrm{~g} /$ day) was much more effective at preventing relapse than a low dose $(0.5 \mathrm{~g} /$ day, Table IV). It has previously been reported that recurrence is more common in patients who have recently relapsed. ${ }^{417}$ The reason for this is not clear, but microscopic evidence of inflammation often persists despite clinical and sigmoidoscopic remission and may predict relapse. ${ }^{18}$ Therefore, a higher luminal concentration of 5-ASA may be necessary in the early stages of remission. For those in longer term remission, dose is less important and $0.5 \mathrm{~g} /$ day seems to be as effective as a higher dose after two years in remission.

Clinical use of a drug depends on a balance between efficacy and adverse effects. The only side effect of olsalazine that occurs with any frequency is diarrhoea, which can be distinguished from a relapse by the absence of blood and the lack of inflammation at sigmoidoscopy. Diarrhoea is a result of the action of intact olsalazine on the small intestine, ${ }^{19}$ which seems to be due to an unusual combination of stimulating bicarbonate, chloride, and water secretion and inhibiting absorption. ${ }^{2021}$ In the current study, enteric coated olsalazine was formulated in an attempt to reduce the frequency of diarrhoea. Loose motions or diarrhoea affected $28 \%$, however, and was related to dose, although the drug had to be withdrawn in only $12 \%$ who were mostly taking $2 \mathrm{~g} /$ day (Table V). Diarrhoea usually started shortly after beginning the drug, but did not occur for several weeks in some patients (Table V). The high incidence of loose motions may be a result of meticulous reporting of side effects, including those who had looser motions than previously. This was to the advantage of some patients who had a tendency to constipation with proctitis or distal disease. It is also possible that the enteric coated formulation, contrary to expectations, could have contributed to the relatively high incidence of diarrhoea. Although some patients were particularly sensitive to diarrhoea (including two who had to be withdrawn when taking $0.5 \mathrm{~g} /$ day), it could often be mitigated by ensuring that the drug was taken with meals. It was anticipated that diarrhoea would predominantly affect patients with extensive disease as a result of impairment of colonic electrolyte and water reabsorption mechanisms. Subgroup analysis failed to confirm this, however, possibly because numbers were small. Compared with $1 \mathrm{~g} /$ day, a dose of $2 \mathrm{~g} /$ day improves the remission rate from 70 to $78 \%$ at one year, but increases the withdrawal because of diarrhoea 
from 9 to $19 \%$. It is difficult to explain why the patients who had been in remission for longest seemed to be the most sensitive to this side effect (Table V), although dose seems to be less important for efficacy in this group (Table IV). The optimum balance between these factors seems to be achieved with $1 \mathrm{~g} /$ day. However, proximal constipation is a common clinical problem in distal colitis ${ }^{22}$ and olsalazine-induced loosening of stools may be turned to therapeutic advantage in some patients.

It can be concluded that a maintenance dose of $2 \mathrm{~g} /$ day is recommended for patients with proctitis or for those who have had a recent relapse, if this can be tolerated. Should diarrhoea occur, temporary reduction in the dose and ensuring that the drug is taken with meals may help. The dose of olsalazine necessary to maintain remission is less important for patients with extensive disease, but $0.5 \mathrm{~g}$ /day is ineffective for patients who have been in remission for less than 12 months. For most patients the optimum dose of olsalazine is $1 \mathrm{~g} /$ day.

We are most grateful to our patients for cooperating with the trial and to Sven Ljungberg, Per-Âke Sandvold, Helena Eriksson, and Gary Jansson of Pharmacia (AB), Sweden for financial support and for help in analysing the data.

Some of the data have previously been presented to the British Society of Gastroenterology (Gut 1992; 33: T159.

1 Das KM, Eastwood MA, McManus JPA, Sircus W. Adverse reactions during salicylazosulfapyridine therapy and the relation with drug metabolism and acetylator phenotype. N Engl f Med 1973; 289: 491-5.

2 Truelove SC. Evolution of olsalazine. Scand $\mathcal{f}$ Gastroenterol 1988; 23 (suppl 148): 3-6.

3 Wadworth AN, Fitton A. Olsalazine. A review of its pharmacodynamic and pharmacokinetic properties and therapeutic potential in inflammatory bowel disease. Drugs 1991; 41: 647-64.

4 Sandberg-Gertzén H, Järnerot G, Kraaz W. Azodisal sodium in the treatment of ulcerative colitis. A study of tolerance and relapse - prevention properties. Gastroenterology 1986; 90: 1024-30.
5 Ireland A, Mason CH, Jewell DP. A controlled trial comparing olsalazine and sulphasalazine for the maintenance treatment of ulcerative colitis. Gut 1988; 29: 835-7.

6 Kiilerich S, Ladefoged K, Rannem T, Ranlov PJ. Prophylactic effects of olsalazine $v$ sulphasalazine during 12 months maintenance treatment of ulcerative colitis. The Danish Olsalazine Study Group. Gut 1992; 33: 252-5.

7 Azad Khan AK, Howes DT, Piris J, Truelove SC. Optimum dose of sulphasalazine for maintenance therapy in dose of sulphasalazine for maintenanc

8 Meyers S, Sachar DB, Present DH, Janowitz HD. Olsalazine in the treatment of ulcerative colitis among patients intolerant of sulphasalazine: a prospective, randomized, placebo-controlled, double-blind, doseranging clinical trial. Gastroenterology 1987; 93: 1255-62.

9 Järnerot G. Clinical tolerance of olsalazine. Scand $\mathcal{F}$ Gastroenterol 1988; 23 (suppl 148): 21-3.

10 Dick AP, Grayson MJ, Carpenter RG, Petrie A. Controlled trial of sulphasalazine in the treatment of ulcerative colitis. Gut 1964; 5: 437-42.

11 Armitage P, Berry G. Statistical methods in medical research. Oxford: Blackwell Scientific Publications. 2nd Ed. 1987; 372-3.

12 Giaffer $\mathrm{MH}$, Holdsworth CD, Lennard-Jones JE, Rodrigues CA, McIntyre PB, Manjunatha S. Improved maintenance of remission in ulcerative colitis by balsalazide $4 \mathrm{~g} /$ day compared with 2 g/day. Alimentary Pharmacology and Therapeutics 1992; 6: 479-85.

13 Järnerot $G$. The new salicylates as maintenance treatment in ulcerative colitis. Gut (in press).

14 Willoughby $\mathrm{CP}$, Aronson JK, Agback H, Bodin NO, Truelove SC. Distribution and metabolism in healthy volunteers of disodium azodisalicylate, a potential therapeutic agent for ulcerative colitis. Gut 1982; 23: 1081-7.

15 Ireland A, Jewell DP. Mechanism of action of 5-aminosalicylic acid and its derivatives. Clin Sci 1990; 78: 119-25.

16 De Vos M, Verdievel H, Schoonjans R, Praet M, Bogaert $M$, Barbier F. Concentrations of 5-ASA and Ac-ASA in human ileocolonic biopsy homogenates after oral 5-ASA preparations. Gut 1992; 33: 1338-42.

17 Riley SA, Mani V, Goodman MJ, Lucas S. Why do patients with ulcerative colitis relapse? Gut 1990; 31: 179-83.

18 Riley SA, Mani V, Goodman MJ, Dutt S, Herd ME. Microscopic activity in ulcerative colitis: what does it mean? Gut 1991; 32: 174-8.

19 Mohsen AQM, Mulvey D, Priddle JD, Parsons DS, Jewell DP. Effects of olsalazine in the jejunum of the rat. Gut 1987; 28: 346-52.

20 Pamucku R, Hanauer SB, Chang EB. Effect of disodium azodisalicylate on electrolyte transport in rabbit ileum and colon in vitro. Comparison with sulfasalazine and 5-aminosalicylic acid. Gastroenterology 1988; 95: 975-81.

21 Raimundo AH, Patil DH, Frost PG, Silk BD. Effects of olsalazine, and sulphasalazine on jejunal and ileal water and electrolyte absorption in normal human subjects. Gut 1991; 32: 270-4.

22 Rao SSC, Holdsworth CD, Read NW. Symptoms and stool patterns in patients with ulcerative colitis. Gut 1988; 29: $342-5$. 